\title{
MODELLING THE UPTAKE OF SOIL WATER AT DIFFERENT DEPTHS BY TEA (CAMELLIA SINENSIS) PLANTS
}

\author{
R.P. DE SILVA \\ Department of Agricultural and Plantation Engineering, The Open University, Nawala, \\ Nugegoda.
}

(Received: 19 January 2000 ; accepted: 11 July 2000)

\begin{abstract}
A multi-layer soil water use model to simulate the extraction of soil water by a tea crop was developed and tested with experimental data fiom Tanzania. The predictions of moisture contents at different deptlis in the soil profile at different dates through the model agreed well with experimental data.
\end{abstract}

Keywords: Camellia sinensis, Soil water use model, Tea

\section{INTRODUC'TION}

Soil moisture content and its distribution with respect to both time and depth are key factors governing some hydrological processes that have important economic consequences in land and water management. For example, the efficient use of irrigation water, the effective operation of flood warning systems and the accurate assessment of ground water recharge are all dependent upon the availability of reliable soil moisture data, because they incorporate elements which are sensitive to soil moisture status. There is therefore a need for models that can accurately simulate soil moisture content and its distribution for any set of meteorological, soil and plant conditions ${ }^{1}$.

Improved understanding of any of the processes of the tea crop is important to Sri Lanka, because tea (Camellia sinensis) is one of the major export crops bringing in much needed foreign exchange to the country. Tea plants, particularly some vegetatively propagated clones are prone to drought which occurs annually specially under low country conditions. As a result there have been reduced crop yields and in some cases the failure of the crop altogether prompting the authorities to think of irrigating the tea crop as in some foreign countries. Therefore, a study on understanding the extraction of soil water at different depths by a tea crop was undertaken. This paper describes the development of a multi-layer soil water use model (capable of predicting water use at different depths in the soil profile by a tea crop) that is tested with field data from Tanzania.

\section{Models to simulate soil water uptake in a Tea Crop}

Although water use/extraction of many of the plants have been modelled, not much work has been done on the water use/extraction by a tea crop. Willat ${ }^{2}$, Cooper ${ }^{3}$ and Stephens \& Carr $^{4}$ have modelled the water use of tea which gives the amount of 
water use by the whole plant rather than the extraction pattern of the root system. Willat ${ }^{2}$ working in Malawi, using gravimetric sampling, found a hysteretic relation between the actual ( $\mathrm{ETa}$ ) and potential ( $\mathrm{ETp}$ ) evapotranspiration $(0.85-0.90)$ and a critical soil moisture deficit $(200 \mathrm{~mm})$, above which the ratio ETa/ETp fell sharply. Cooper ${ }^{3}$ found this ratio to be 0.56 and little effect of water stress on the transpiration rate from his work in Kenya. Stephens \& Carr ${ }^{4}$, from their work in Tanzania have come up with a single layer water use model, which predicts the water use very well. Also they have identified the critical soil water deficit for clone ' $6 / 8$ ' as $60 \mathrm{~mm}$.

From these few instances of modelling the water use of tea, it is clear that simulating the water use of tea has been studied only superficially up to now. Further studies on simulating the water use by a tea crop are therefore warranted.

\section{METHODS AND MATERIALS}

The location chosen to develop and test the model was Ngwazi $\left(8^{\circ} 33^{\prime} \mathrm{S}, 35^{\circ} 10^{\prime} \mathrm{E}\right.$, altitude $1840 \mathrm{~m}$ ) in Tanzania. The annual rainfall ranges from 800 to $1100 \mathrm{~mm}$, with most rain falling between mid November and May. Pan evaporation rates range from approximately $3 \mathrm{~mm} / \mathrm{d}$ from June to $5 \mathrm{~mm} / \mathrm{d}$ in October. The soil at Ngwazi is intensely weathered, well drained \& acidic with a low base status typical of the grasslands in the area. In general the soils up to $5.5 \mathrm{~m}$ (maximum rooting depth of tea) can be classified as clayey. A detailed description of the climate and soil at Ngwazi is given by Stephens \& Carr. ${ }^{4}$

The model: The model is based on the approach use $1 \mathrm{by}$ Carr et al ${ }^{5}$ for predicting the water use by potatoes and sugarbeet with improvements and suitable modifications for the tea plant. These improvements and modifications are described and discussed later in this paper. A brief description of the model developed is given in the Appendix. A detailed description (and a flowchart) is found in de Silva. ${ }^{\circ}$

The calculations to determine the volumetric soil water content at a particular depth in the soil profile at a given day (or indirectly, water extraction by plant roots) is given below.

1. Reference crop evapotranspiration is partitioned between the substrate and crop evaporation.

2. Evaporation of water from temporary storage on the soil surface and draining through the surface layers is calculated, and moisture contents of the layers adjusted accordingly.

3. Soil water evaporation is calculated and removed initially from the layer nearest the surface and then in sequence through the remaining layers. 
Total available water is removed from the top layer before extraction from the next layer begins. Moisture contents of the layers are adjusted again.

4. Evaporation due to interception is determined and taken off from the potential crop evaporation to determine the potential transpiration.

5. Actual transpiration is determined using the rooting density, evaporation rate and available water functions.

6. Volumetric water content of each layer is determined by considering the water balance of each layer for the specified time interval.

The modifications done on the Carr et $a l^{5}$ model given above, are as follows.

1. In calculating the depth of water temporarily stored in the soil profile, a temporary storage zone is identified and evaporation from soil is calculated based on this zone.

2. Figures by Cooper: for interception are made use in calculating potential evaporation from water intercepted by the crop.

3. Water is extracted from the layers with the highest soil water potential (SWP) rather than the layer with highest soil moisture content.

4. In extracting water from a layer, a very small quantity (say, $0.001 \mathrm{~m} / \mathrm{m}$ or smaller) is extracted from the layer with highest SWP, and then moisture contents of the layers are adjusted and SWP of each layer recalculated. Again the extraction takes place from the layer with the highest SWP and this process is continued until the evaporative demand for the day is satisfied and/ or the soil profile runs dry. This method is thought to be better than extracting the difference in moisture content between the two wettest layers, which seems to have the following shortcomings.

1. Consider the soil profile shown in Fig. 1.

In extracting the difference between the two wettest layers, an amount equal to $(0.30-0.24)$ will be extracted from layer 1 (assuming evaporative demand to be higher than this and it is possible to extract this amount from layer 1). However, when a very small quantity is extracted from the wettest layer (layer 1), it no longer becomes the wettest layer and in fact extraction should take place from a different layer (layer 2 in this example). 


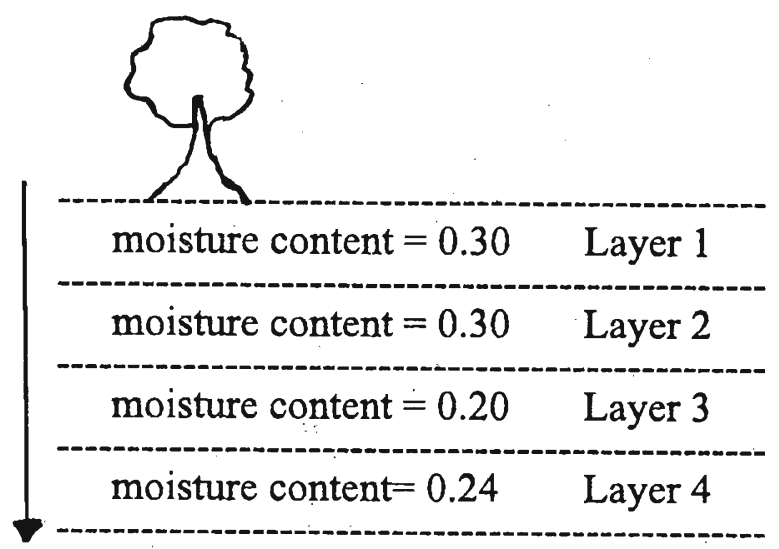

\section{Figure 1: A soil profile with different moisture contents at different layers}

With the proposed method, where a small quantity is extracted from the layer (with highest SWP), this problem does not arise, because after extracting this very small quantity, SWP of each layer is recalculated to identify the layer with highest SWP.

2. Also, the transpiration restriction functions $\mathrm{FW}_{\mathrm{w}}$ and $\mathrm{Fr}$ are more easily calculated with the proposed method, since they (especially Fw) change with the changing moisture content in the profile.

Testing of the model: A computer program written in Fortran 77 was used to simulate the daily water contents down the root zone profile, with the modified method outlined in the previous section. Performance of the model was tested with data from work carried out by Stephens and Carr ${ }^{4}$ in Ngwazi Tea Research Unit, in the Mufindi District of Tanzania.

The maximum rooting depth used was $5.0 \mathrm{~m}$ and the rate of root growth was assumed to be zero, since the testing was done for mature, fully grown tea. The root zone was divided into 25 layers with a layer thickness of $200 \mathrm{~mm}$ each. The ratio between actual soil evaporation and potential soil evaporation of each layer was taken as $1.0,0.5,0.1$ for the top three layers and zero for the other layers. ${ }^{7}$

The root zone consisted of five different soil horizons. Field capacity, permanent wilting point and moisture content at $-200 \mathrm{kPa}\left(\theta_{\mathrm{R}}\right)$ for each soil horizon is shown in Table 1. An irrigation treatment (I0) was used for testing of the model. Fig. 2 shows the rainfall, pan evaporation and the irrigation (I0) during the period of testing (i.e., from 1 April 1989 to 1 December 1989). 
Table 1: Field Capacity at $\mathbf{- 3 3 0} \mathrm{kPa}$ (FC), Permanent wilting point at $\mathbf{- 1 5 0 0 \mathrm { kPa }}$ (PWP) and moisture content at $-200 \mathrm{kPa}\left(\theta_{\mathrm{R}}\right)$ for each soil horizon.

\begin{tabular}{lcccc}
\hline $\begin{array}{l}\text { Soil } \\
\text { horizon }\end{array}$ & $\begin{array}{c}\text { Depth } \\
\text { range }(\mathrm{cm})\end{array}$ & $\begin{array}{c}\text { Field Capacity } \\
(\mathrm{FC})\end{array}$ & $\begin{array}{c}\text { Permanent } \\
\text { Wilting Point } \\
(\mathrm{PWP})\end{array}$ & $\begin{array}{c}\text { Moisture content } \\
\text { at } \\
-200 \mathrm{kPa}\left(\theta_{\mathrm{R}}\right)\end{array}$ \\
\hline 1 & $0-40$ & 0.26 & 0.17 & 0.22 \\
2 & $40-120$ & 0.28 & 0.22 & 0.24 \\
3 & $120-220$ & 0.31 & 0.23 & 0.25 \\
4 & $220-360$ & 0.34 & 0.28 & 0.30 \\
5 & $360-500$ & 0.32 & 0.26 & 0.29 \\
\hline
\end{tabular}

\section{RESULTS}

Fig. 3 shows the experimentally determined soil water deficit and the soil water deficit predicted by the model. From Fig. 3, it is clear that the agreement between values predicted by the model and actual values of soil water deficit is very good.

Fig. 4 shows the calculated \& measured water contents for each layer on three different occasions (i.e., on 3 May, 8 July and 10 November) for treatment I0. The best agreement between calculated and measured values is for 3 May 1989 .

However, on 8 July the model seem to have extracted less from depths between $0.8 \mathrm{~m}-1.5 \mathrm{~m}$ and more from depths between $2.2 \mathrm{~m}-3.5 \mathrm{~m}$. The agreement between calculated \& measured values for other depths seems very good. This difference could be due to the following reasons.

1. Apart from the three factors used in the model, which restricts the transpiration under non-ideal conditions, there may be other factors which could restrict the transpiration. Stage of growth of roots in particular layer (i.e., age of roots), density of roots in a layer rather than above a certain depth (critical depth) could be some of them. If this is the case, it explains the difference in results for depth range $2.2 \mathrm{~m}-3.5 \mathrm{~m}$, where the model has extracted more water.

2. The model was found to be very sensitive to the soil water release curve (SWRC). A small inaccuracy in SWRC could well result in a discrepancy, since, the model extracts water always from the layer with the highest soil water potential.

3. The redistribution of water once an amount is extracted from a soil layer. Redistribution does not seem to affect the total soil water extracted for the season (since the measured \& calculated SWD tally very well), but could have 
an effect when it comes to the extraction from the individual layers. However, this is not very likely since extraction patterns agree on some other days like 3 May.

The results for 10 November agrees quite well with measured values except for depths between $0.4 \mathrm{~m}$ and $2.0 \mathrm{~m}$. This could well be due to the values specified for permanent wilting point (higher values were used in the model) apart from the reasons mentioned above.
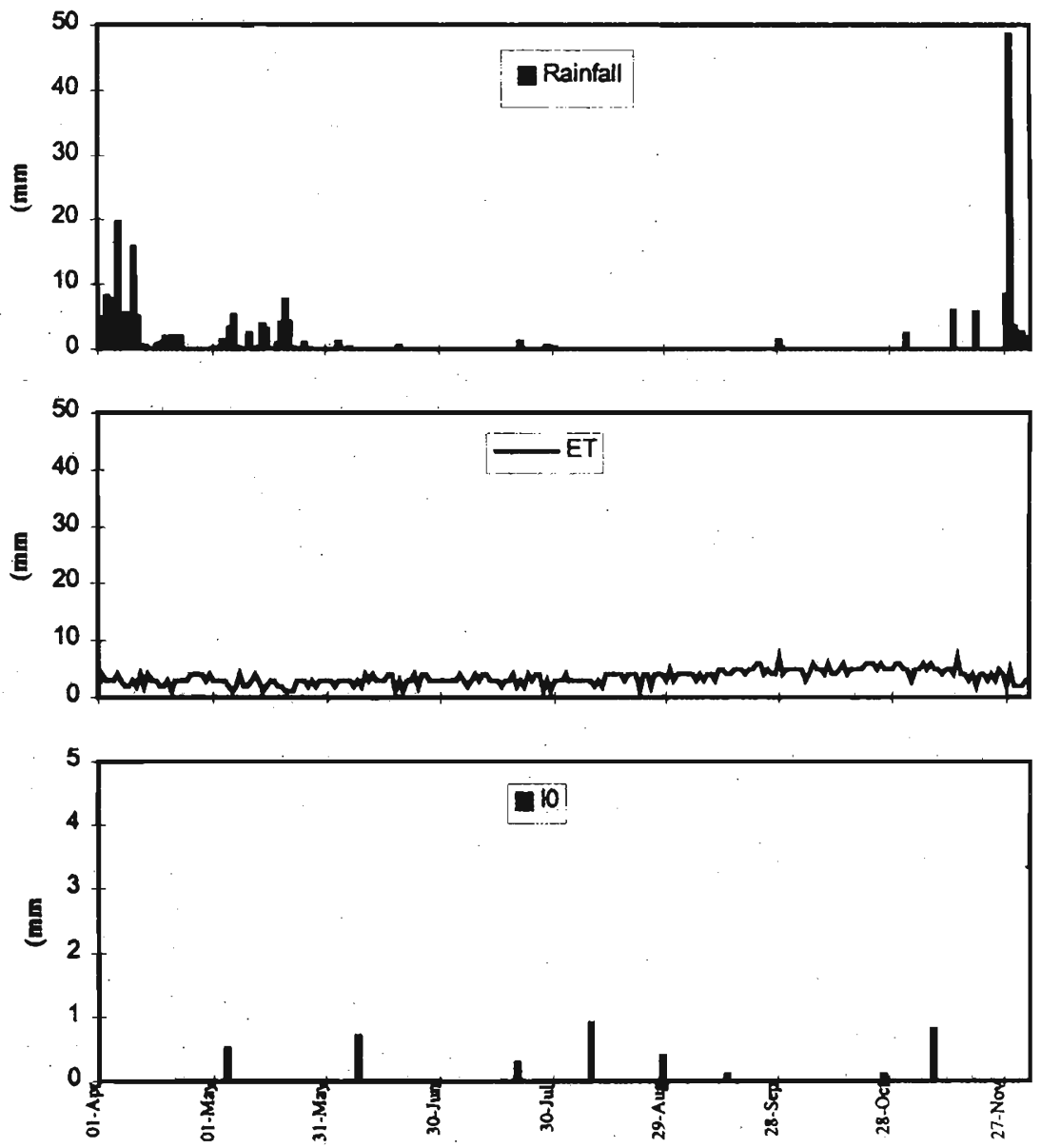

Figure 2: Rain, Pan evaporation and Irrigation treatment (I0) used during the period of testing the model

In general, it is seen that the model predicted moisture contents agree quite well with the experimentally measured moisture contents. 


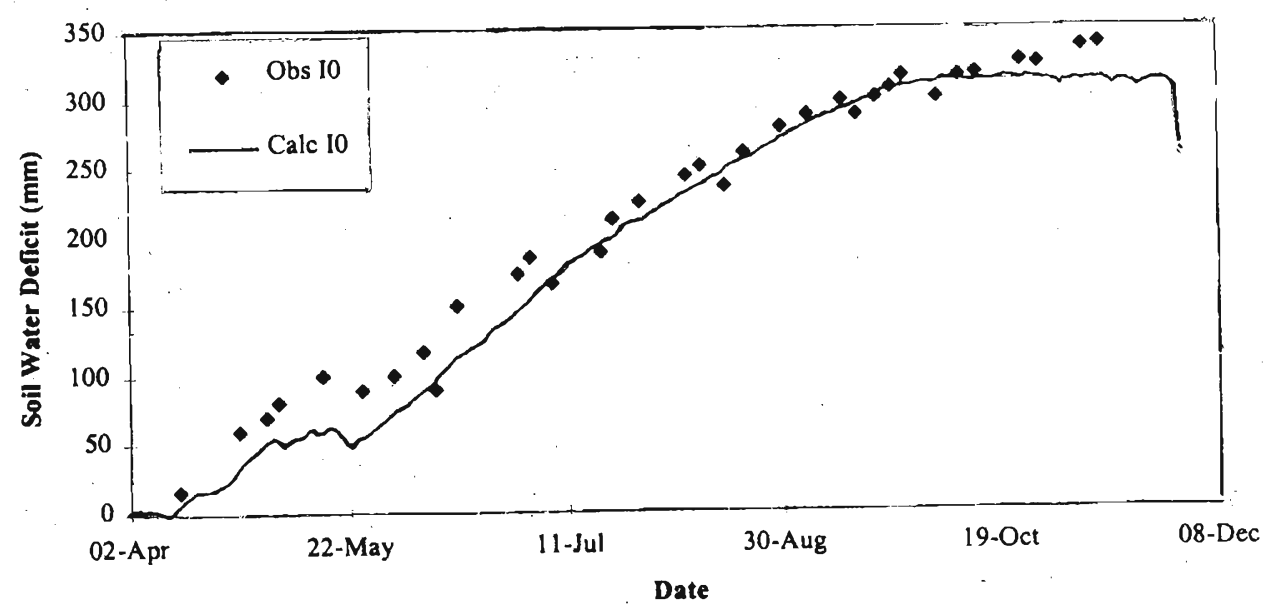

Figure 3: Predicted and experimentally determined soil water deficit for irrigation treatment $\mathrm{IO}$.

\section{DISCUSSION}

The model predicted moisture contents on 6 different days are shown in Fig. 5 . It is seen that initially the tea crop seem to extract water from the surface layers of the soil profile (as there is no change in moisture contents at depths below $2.5 \mathrm{~m}$ on $10^{\text {th }}$ May). However, when the soil profile dries further, it is seen that the tea crop has extracted water from all layers up to the depth of $5.0 \mathrm{~m}$, which is the maximum root depth. This finding will have important implications in irrigating a tea crop and also in the application of fertiliser to a tea crop (as nutrients are likely to be absorbed with soil water).

In the approach used in this model, a number of simplifying assumptions were made, which have to be reconsidered and rectified if the accuracy of the predictions are to be very high. Instantaneous water movement down the profile was assumed in calculating drainage through the layers. For the conditions tested, this is unlikely to cause a significant error, because of the small amounts of water inputs (i.e., rain \& irrigation). However, for a season where a large quantity of water is applied to the root zone, predictions could be inaccurate. Therefore, it is recommended that the rate of water movement through the layers be considered and built into the model for it to be more accurate.

Redistribution of soil water at different layers in the soil profile was assumed to be negligible. For improved accuracy a mechanism must be built in to the model which carries out the redistribution. Also the upward movement of soil water from depths greater than $5.0 \mathrm{~m}$ (as the soil layers above this depth dries out) was assumed negligible. This assumption can also be treated as redistribution of soil water and must be taken into consideration for improved accuracy. 


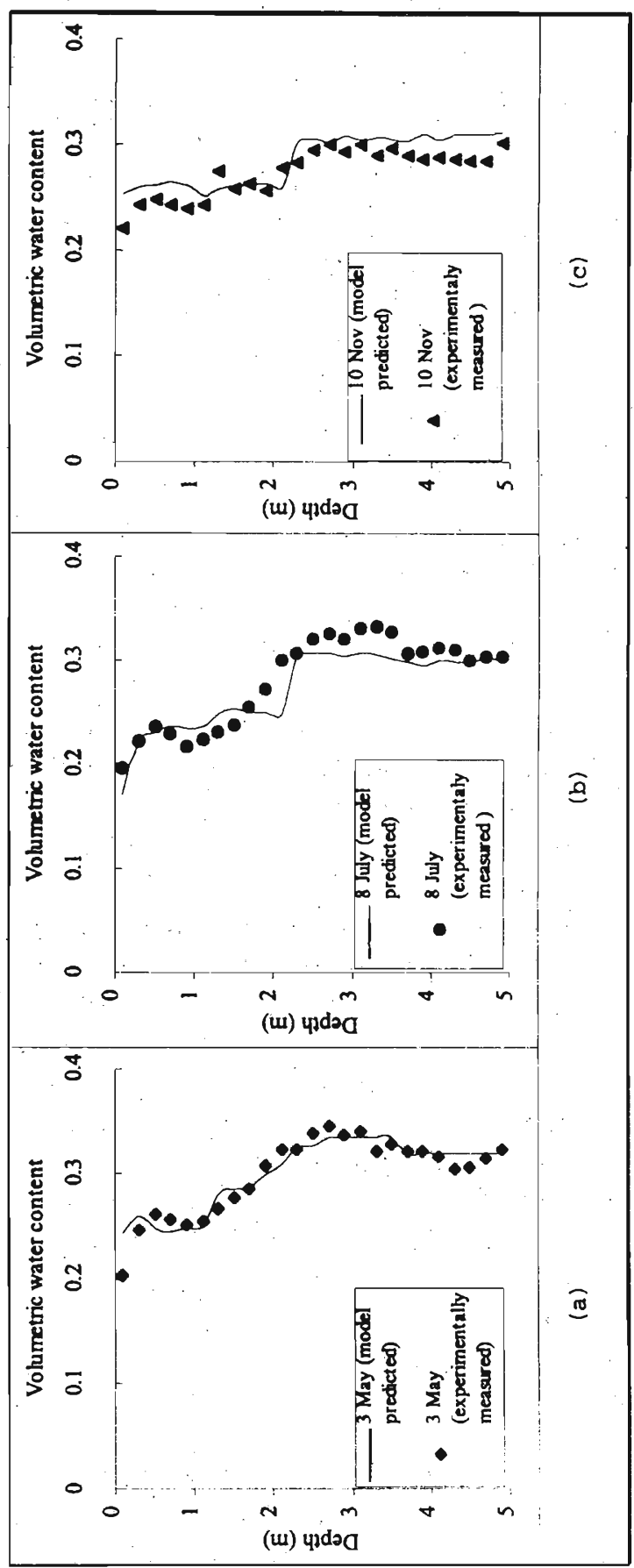

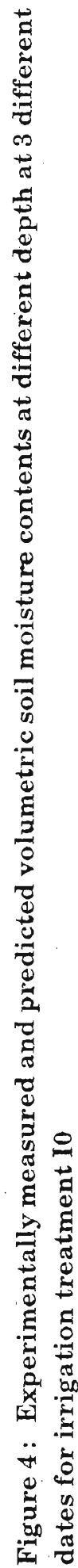




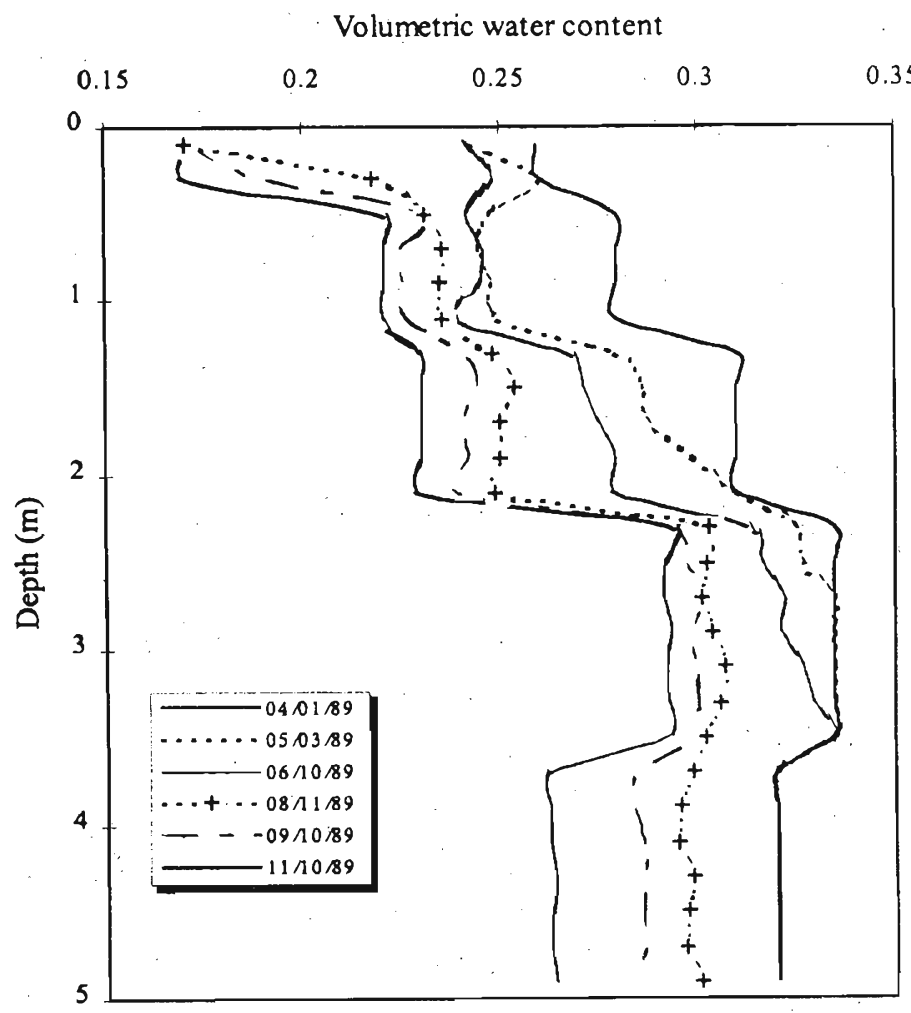

Figure 5: Model predicted soil water content at different depths on 6 different dates in 1989

Some work also has to be done in the area where soil evaporation was calculated. The approach used would depend largely on the soil condition and the climate of the testing site. If this method is to be used for a particular site, the ratio between actual and potential evaporation has to be determined (also considering the layer thickness) for each layer. However, since the amount of evaporation from substrate in a crop like tea is very small, an inaccuracy in the soil evaporation will not be reflected in the predictions significantly.

The amount of evaporation due to interception was calculated according to the information available as at present. It is felt that there is room for improvement here as well, although the figures used seem to give an accurate prediction over the. dry season when there was little or no rain.

The conclusions of this study are;

1. It is possible to successfully model the water use by a tea crop using a simple, multi-layer water balance model. 
2. The model developed performs well in predicting the soil water use at different depths in a soil profile by a tea crop.

\section{Acknowledgement}

I thank Dr W. Stephens of Silsoe College, Cranfield University, UK for supervising this project and also for providing with field data from Tanzania.

\section{References}

1. Wally W. J. \& Hussein D. E. D. A. (1982). Development and testing of a general purpose soil moisture-plant model. Journal of Hydrological Sciences 27: $1-17$.

2. Willat S. T. (1971). Model of soil water use by tea. Agricultural Meteorology 8: 341 - 351.

3. Cooper J.D. (1979). Water use of a tea estate from soil moisture measurements. East African Agriculture \& Forestry Journal 43: 102 - 121.

4. Stephens William \& Carr M. K. V. (1991). Responses of tea (Camellia sinensis) to irrigation and fertilizer II. Water use. Experimental Agriculture 27: $193-210$.

5. Carr M. K. V., Wright E. \& Hamer P. J. C. (1991). Irrigation of field vegetable $\&$ arable crops. Final report to the Ministry of Agriculture, Fisheries \& Food. Silsoe College, Silsoe, Bedford MK45 4DT.

6. De Silva R. P. (1991). A multi layer soil water use model for tea. MSc Thesis, Silsoe College, Cranfield University, UK.

7. Smith L. P. \& Douglas H. A. (1975). Theoretical considerations of the water loss by evaporation from bare soil \& the effect of partial crop cover. Agricultural Development Advisory Service, Quarterly Review 16: 135 - 144

8. Aslyng H. C. \& Hansen S. (1982). Water balance \& crop production simulation. Hydrotechnical Laboratory, The Royal Veterinary \& Agricultural University, Copenhegan.

9. Squire G. R. \& Callander B. A. (1981). Tea plantations. In: Water Deficits \& Plant Growth 6. (Ed. T. T. Kozlowski) pp. 471-510. Academic Press, New York. 
10. Denmead O. T. \& Show R. H. (1962). Availability of soil water to plants as affected by soil moisture content \& meterological conditions. Agronomy Journal 54: 385-390

11. Slatyer R. O. (1967). Plant water relationships, Academic Press, New York, $357 \mathrm{pp}$.

\section{APPENDIX}

The evaporative demand of the atmosphere (potential evapotranspiration ETp) can be considered to be satisfied by the crop evapotranspiration (Ecrop) and by the substrate evaporation (Esub) as in equation (1).

$$
E T p=E c r o p+E s u b
$$

The potential evpoatranspiration (ETp) is also given by

$$
E T p=K c \times E T D
$$

where $\mathrm{Kc}=$ crop factor and $\mathrm{ETo}=$ reference crop evapotranspiration

In order to estimate substrate evaporation (Esub) and crop evaporation (Ecrop) independently, it is necessary to partition the available energy for evaporation between these two sources. This is done as in Aslyng \& Hansen. ${ }^{.}$

$$
\begin{aligned}
& E^{*} s u b=(1-\alpha) \times K c \times E T o \\
& E^{*} c r o p=\alpha \times K c \times E T o
\end{aligned}
$$

Calculation of $\alpha$ is carried out as follows.

$$
\begin{aligned}
& \text { When } 0<\mathrm{Si} / \mathrm{S}<0.5 ; \alpha=1.8 \times \mathrm{Si} / \mathrm{S} ; \mathrm{K}_{c}=1+2 \mathrm{xSi} / \mathrm{S} \\
& \text { When } \mathrm{Si} / \mathrm{S}>0.5 ; \alpha=0.9 ; \mathrm{K}_{c}=\mathrm{K}_{c}(\max )
\end{aligned}
$$

Where ;

$$
\begin{array}{ll}
\mathrm{Si} & =\text { amount of solar radiation intercepted by the crop canopy } \\
\mathrm{S} & =\text { incoming solar radiation } \\
\alpha & =\text { a weighting factor } \\
\mathrm{Kc}(\max ) & =\text { maximum value of the crop coefficient }
\end{array}
$$




\section{A.1 Substrate Evaporation (Esub)}

Water loss by evaporation from the substrate or the soil surface is derived from two sources.

\section{A.1.1 Evaporation due to Temporary Storage (Ef)}

This is the evaporation of water which is temporarily stored on the surface of the soil or moving down through the larger pores of coarse textured soils. This is assumed only to occur within 24 hours of a rainfall or an irrigation event which was greater than the existing soil water deficit, and before free drainage has ceased.

To calculate evaporation due to temporary storage, a temporary storage zone (TSZ) is defined as the depth of water which moves down the profile in a day. This can be considered as equal to the vertical saturated hydraulic conductivity of the soil layer.

The depth of water (Wf) temporarily stored in the temporary storage zone is determined as follows.

$$
\begin{aligned}
& \text { When } \mathrm{P}+\mathrm{I}>\mathrm{SWD} ; W f=P+I-S W D \\
& \text { When } \mathrm{P}+\mathrm{I}<\mathrm{SWD} ; W f=0
\end{aligned}
$$

Where

$$
\begin{aligned}
& \mathrm{P}=\text { previous day's precipitation } \\
& \mathrm{I} \quad=\text { previous day's irrigation } \\
& \mathrm{SWD}=\text { soil water deficit in the temporary storage zone }
\end{aligned}
$$

Two cases have to be considered depending on whether or not the amount of temporary storage exceeds the potential evaporation rate at the soil surface.

(a) When $E^{*}$ sub $<$ Wf; $E f=E^{*} s u b ; E^{*} s=0 ; d=W f-E f$

(b) When $\mathrm{E}^{*}$ sub $\geq W f ; E f=W f ; E^{*} s=E^{*}$ sub.VIf; $d=0$

Where

$\mathrm{E}^{*} \mathrm{sub}=$ potential evaporation rate of the substrate.

$\mathrm{E}^{*} \mathrm{~S}=$ potential evaporation rate of the soil

$\mathrm{d}=$ drainage 


\section{A.1.2 Evaporation Due To Soil Water (Es)}

Here the root zone is divided into a number of layers and evaporation from each layer is taken as a factor of the potential soil water evaporation as shown in Table A.1. ${ }^{7}$ These factors depend on the required layer thickness, soil texture, soil structure etc.

Table A.1: Maximum soil water evaporation which can occur from individual soil layers expressed as a ratio of the potential soil water evaporation (E*s). Layer 1 is at the surface.

\begin{tabular}{lcccccr}
\hline Layer number & 1 & 2 & 3 & 4 & 5 & $6-9$ \\
\hline Es/E & 1.00 & 0.67 & 0.33 & 0.20 & 0.10 & 0.05 \\
\hline
\end{tabular}

\section{A.2 Crop Evaporation (Ecrop)}

Water lost by evaporation from the crop (Ecrop) is derived from two sources.

\section{A.2.1 Evaporation due to Intercepted Water (Ew)}

This is the rain or irrigation water which is intercepted by and wets the crop canopy. Squire \& Callander" reports a maximum canopy storage of $2 \mathrm{~mm}$ and an average of only $0.8 \mathrm{~mm}$. Further, they suggest a tentative estimate of canopy storage of $1 \mathrm{~mm}$ for 'Assam' type tea in the absence of a reliable value. However, since the variation of amount intercepted with rainfall is given by Cooper", his figures are used in this model and the potential evaporation due to intercepted water $\left(\mathrm{E}^{*} \mathrm{w}\right)$ is determined as follows.

$$
\begin{aligned}
& \text { When } P+I=0 ; E^{*} w=0 \\
& 0<P+I \leq 7.5 \mathrm{~mm} ; E^{*} w=0.33(P+I) \\
& P+I>7.5 \mathrm{~mm} ; E^{*} w=2.5 \mathrm{~mm} .
\end{aligned}
$$

The following two cases have to be considered.

(a) When $E^{*}$ crop $\geq E^{*} w ; E w=E^{*} w ; E^{*} t=E^{*}$ crop-Ew

(b) When $\mathrm{E}^{*}$ crop $<\mathrm{E}^{*} \mathrm{w} ; \mathrm{Ew}=\mathrm{Ew} \mathrm{E}^{*}$ crop; $\mathrm{E}^{*} \mathrm{t}=0$

Where $\mathrm{E}^{*} \mathrm{t}$ is the potential transpiration.

\section{A.2.2 Transpiration (Et)}

This is water which diffuses through the stomatal pores as vapour into the surrounding air and will be equal to its potential value under certain ideal 
conditions only. At all other times it is less than the potential value. The point at which the actual transpiration falls below the potential rate is not fixed and it depends on many variables including soil hydraulic characteristics, rooting density and the potential evaporation rate. ${ }^{10,11}$ Thus the transpiration is calculated as follows.

$$
E t=E^{*} t . F r . F e . F w
$$

Where

$\mathrm{Fr}=\mathrm{a}$ function of the rooting density

$\mathrm{Fe}=\mathrm{a}$ function of the prevailing evaporation rate

$\mathrm{Fw}_{\mathrm{w}}=\mathrm{a}$ function of the available water content of the soil

The function $\mathrm{Fr}$ is calculated as follows.

$$
\begin{aligned}
& \text { When } 0 \leq \mathrm{Rd} \leq \mathrm{Rc} ; \mathrm{Fr}=1.0 \\
& \mathrm{Rc}<\mathrm{Rd} \leq \mathrm{Rm} ; \mathrm{Fr}=\left(\theta_{\mathrm{FC}}-\theta_{\mathrm{K}}\right) /\left(\theta_{\mathrm{FC}}-\theta_{\mathrm{PWP}}\right)
\end{aligned}
$$

Where ;

$$
\begin{aligned}
& R_{\mathrm{c}}=\text { rooting depth within which the density of roots is large } \\
& \mathrm{R}_{\mathrm{d}}=\text { depth at which water extraction takes place } \\
& \mathrm{R}_{\mathrm{m}}=\text { maximum rooting depth expected } \\
& \Theta_{\mathrm{FC}}=\text { moisture content at field capacity } \\
& \theta_{\mathrm{PW}}=\text { moisture content at permanent wilting point } \\
& \theta_{\mathrm{K}}=\text { moisture content at soil water potential of }-200 \mathrm{kPa}
\end{aligned}
$$

The evaporation rate function is calculated as follows.

$$
\begin{aligned}
& \theta>\theta_{C} ; \mathrm{Fe}=1.0 \\
& \theta \leq \theta_{C} \& \mathrm{ETo} \leq 5.0 \mathrm{~mm} ; \mathrm{Fe}=1.1-0.04^{*} \mathrm{ETo} \\
& \theta<\theta_{\mathrm{C}} \& \mathrm{ETp}>5.0 ; \mathrm{Fe}=0.9
\end{aligned}
$$

Where $\theta_{\mathrm{C}}$ is the critical soil water content at which transpiration falls below its potential value.

Available water function is determined as given below.

$$
\begin{aligned}
& \mathrm{pF} \leq \mathrm{pF}_{\mathrm{crit}} ; \mathrm{Fw}_{\mathrm{w}}=1.0 \\
& \left.p F_{\text {crit. }}<\mathrm{pF} \leq \mathrm{pF}_{\mathrm{pwp}} ; \mathrm{FW}_{\mathrm{w}}=\left(\mathrm{pF}-\mathrm{pF}_{\mathrm{pwp}}\right) / \mathrm{pF}_{\mathrm{crit}}-\mathrm{pF}_{\mathrm{pwp}}\right) \\
& \mathrm{pF}>\mathrm{pF}_{\mathrm{pwp}} ; \mathrm{Fw}_{\mathrm{w}}=0.0
\end{aligned}
$$


Where,

$\mathrm{pF} \quad=\mathrm{pF}$ value of the water extracting layer

$\mathrm{pF}_{\text {crit }}=\mathrm{pF}$ value above which transpiration is restricted

$\mathrm{pF}_{\mathrm{pwp}}=\mathrm{pF}$ value at permanent wilting point 